\title{
Hypospadias: Evaluation of Therapeutic Outcomes and Sexual Function in Adulthood in a University Hospital Setting
}

\author{
El Hadji Malick Diaw ${ }^{1 *}$, Modou Ndiaye ${ }^{1}$, Ousmane Sow ${ }^{1}$, Abdoulaye Ndiath ${ }^{1}$, Alioune Sarr ${ }^{1}$, \\ Boubacar Fall2 2 , Babacar Sine' ${ }^{1}$, Aboubacar Traore ${ }^{2}$, Abdourahmane Ndong 3 , Cyrille Ze Ondo', \\ Amath Thiam¹, Oumar Gaye1, Ndiaga Seck Ndour'1, Ngor Mack Thiam¹, Yaya Sow ${ }^{1}$, Babacar Diao1, \\ Papa Ahmed Fall ${ }^{4}$, Alain Khassim Ndoye ${ }^{1}$
}

\author{
${ }^{1}$ Urology-Andrology Department, Aristide Le Dantec Hospital, Dakar, Senegal \\ ${ }^{2}$ Urology-Andrology Department, De la Paix Hospital, Ziguinchor, Senegal \\ ${ }^{3}$ Departement of Surgery, Gaston Berger University, Saint-Louis, Senegal \\ ${ }^{4}$ Urology-Andrology Department, Dalal Jamm Hospital, Dakar, Senegal \\ Email: ^el12diaw@gmail.com
}

How to cite this paper: Diaw, E.H.M., Ndiaye, M., Sow, O., Ndiath, A., Sarr, A., Fall, B., Sine, B., Traore, A., Ndong, A., Ze Ondo, C., Thiam, A., Gaye, O., Ndour, N.S., Thiam, N.M., Sow, Y., Diao, B., Fall, P.A. and Ndoye, A.K. (2020) Hypospadias: Evaluation of Therapeutic Outcomes and Sexual Function in Adulthood in a University Hospital Setting. Open Journal of Urology, 10, 245-252.

https://doi.org/10.4236/oju.2020.109029

Received: August 10, 2020

Accepted: September 21, 2020

Published: September 24, 2020

Copyright $\odot 2020$ by author(s) and Scientific Research Publishing Inc. This work is licensed under the Creative Commons Attribution International License (CC BY 4.0).

http://creativecommons.org/licenses/by/4.0/

(c) (i) Open Access

\begin{abstract}
Background: Hypospadias is a congenital malformation resulting from hypoplasia of the tissues forming the ventral face of the penis. It is associated to variable degrees with an ectopic urethral meatus, a penis curvature and a sapper's apron foreskin [1]. The incidence of this malformation varies from country to country. It is estimated at $1 / 300$ male births in France and $0.26 /$ 1000 in Mexico [1]. In Senegal, the prevalence of this malformation is unknown. Hypospadias surgery has improved significantly in recent years due to a better understanding of the anatomy on the one hand and the improvement of the instruments used during surgery on the other (suture material, surgical magnification, urethral catheter of suitable size). In sub-Saharan Africa and particularly in Senegal, hypospadias surgery remains a challenge due to the unavailability of adequate equipment (lack of microsurgical instruments and surgical loupes). Objective: To evaluate the outcomes of the treatment of hypospadias by the different surgical techniques used in our center as well as their sexual function in adulthood. Patients and Methods: This is a retrospective study, including all patients operated for hypospadias between January 2009 and December 2017 in Urology-Andrology department of Aristide Le Dantec hospital. The studied parameters were: frequency, age, clinical and therapeutic aspects, and their sexual function in adulthood after treatment. The outcomes of the treatment were judged good or poor depending of the quality of penile straightening, the aesthetic appearance of the penis, the posi-
\end{abstract}


tion of the urethral neo-meatus, the permeability of the urethra and the existence or not of fistula. The sexual function was assessed by the International Index of Erectile Function 15 (IIEF) score. Results: Fifty-five patients were included. The median age was 6 years ( $\mathrm{P} 25=2.8$ and $\mathrm{P} 75=13$ years). After a mean follow-up of $58 \pm 33$ months, $81.8 \%$ (45) of patients had a good outcome. Duplay-Snodgrass urethroplasty was the most commonly used urethroplasty technique with better results. Complications were noted in $29 \mathrm{pa}$ tients. The most common were urethral fistula, surgical site infection and urethral neo-meatus stenosis. The sexual function was rated good in one patient and average in the other two (after an average decline of $53 \pm 26$ months). Conclusion: Urethroplasty according to Duplay Snodgrass was the most used technique in our studies and its outcomes were better compared to the other techniques used.

\section{Keywords}

Urogenital Malformation, Penile Enlargement, Urethroplasty, Urethrocutaneous Fistula

\section{Introduction}

Hypospadias is a urogenital malformation resulting from hypoplasia of the tissues forming the ventral face of the penis. It is associated to variable degrees with at an ectopic meatus urethral on the ventral side of the penis, a penile curvature and a foreskin in the form of a sapper's apron [1]. This is the second most common malformation in males [2]. Duckett's anatomo-clinical classification was used, distinguishing according to seat meatus hypospadias: the anterior forms (balanic, balano-penile and anterior penile), the middle form and the posterior forms (posterior penile, scrotal and perineal). The location is anterior, median and posterior respectively in $50 \%, 20 \%$ and $30 \%$ of cases [3]. Several surgical techniques were described, justifying the interest in the constant search for effective techniques with the least possible morbidity. Surgery is the standard treatment for hypospadias and several surgical techniques had described in the literature [1] [2] [4]. There are currently more than 400 surgical procedures and their variants without any of it being ideal for the correction of hypospadias. These techniques can be in single or two surgical steps and the choice will depend on the type of hypospadias. Single surgical steps such as the MAGPI, Duplay, Mathieu, Onlay, Duckett techniques adopted in our center seem to be more suitable in our developing countries where the cost of surgery remains inaccessible for the majority of patients. In our context, hypospadias surgery remains a challenge because of several factors interfering with the results. According to Diallo [4] and Diao [5] treatment of hypospadias is fraught with complications due to the conditions in which this type of surgery is performed in our country. The improvement of our outcomes is not only through the training of pediatric urologists 
but also by equipping our countries with microscopic surgery equipment. The objective our study was to evaluate the outcomes of the treatment of hypospadias by the different surgical techniques used in our practice as well as their sexual function in adulthood.

\section{Patients and Methods}

This is a retrospective, descriptive, and single-center study evaluating the outcomes of the hypospadias treatment in Urology-Andrology department of Aristide le Dantec hospital between January 2009 and December 2017. All patients operated on for hypospadias with a complete file were included. Patients with an unusable record, those lost to follow-up and those operated on for hypospadias at least once in another centre were not included. The parameters studied were: age, medical history, clinical, therapeutic aspects and their sexual function in adulthood after treatment. The information was collected by physical examination, review of the records of patients undergoing surgery and a telephone survey. The outcome was judged good if the penis was straightened and the meat us apical with a permeable urethra without urethral fistula. Failure corresponded to recurrent fistulas despite their treatment, total sutures disunity or flap necrosis. The sexual function was assessed with the IIEF-5 questionnaire. The data were recorded and analyzed by IBM SPSS Statistics 24 software.

\section{Results}

Fifty-five patients were included during the study period. The annual incidence was more frequent in 2017 with a percentgae of $23.6 \%(n=13)$. The median age was 6 years (P25 $=2.8$ and P75 $=13$ years). Forty-four patients were brought in for consultation by their parents. Prior hypospadias accounted for $74 \%(n=41)$ of patients. Associated malformations were micropenis $10.9 \%(\mathrm{n}=6)$, cryptorchidism 3.6\% $(\mathrm{n}=2)$, persistence of the peritoneal-vaginal duct $3.6 \%(\mathrm{n}=2)$ and right renal agenesis $1.8 \%(n=1)$. The karyotype performed in 3 patients was normal. All patients were treated with a single surgical step. Adhesion release $(36.4 \%(n=20))$ was the most commonly used types of repair (Table 1$)$. Duplay-Snodgrass urethroplasty was the most commonly used urethroplasty technique $(41.8 \%(\mathrm{n}=23))$ (Table 2). The mean duration of postoperative drainage was $7.4 \pm 3.5$ days (two and 17 days) and was mostly done with a transurethral catheter $(72.7 \%(\mathrm{n}=40))$. Complications were noted in 29 patients and were dominated by urethral fistulas accounting for $51.7 \%(n=15)$ (Figure 1). Fistulae were managed by excision of the fistula pathway followed by separate suture of urethral and cutaneous in the absence of spontaneous closure 3 months after hypospadias. Twelve patients were treated for urethral fistulas. The neo-meatus stenosis was treated with iterative HEGAR candle dilatation with satisfactory results. Residual penile curvature did not require revision surgery. After a mean follow-up of $58 \pm 33$ months (with extremes of two and 10 years), outcomes were good and poor in $81.8 \%$ (45) and $19.2 \%$ (10) of patients, respectively. The 
23

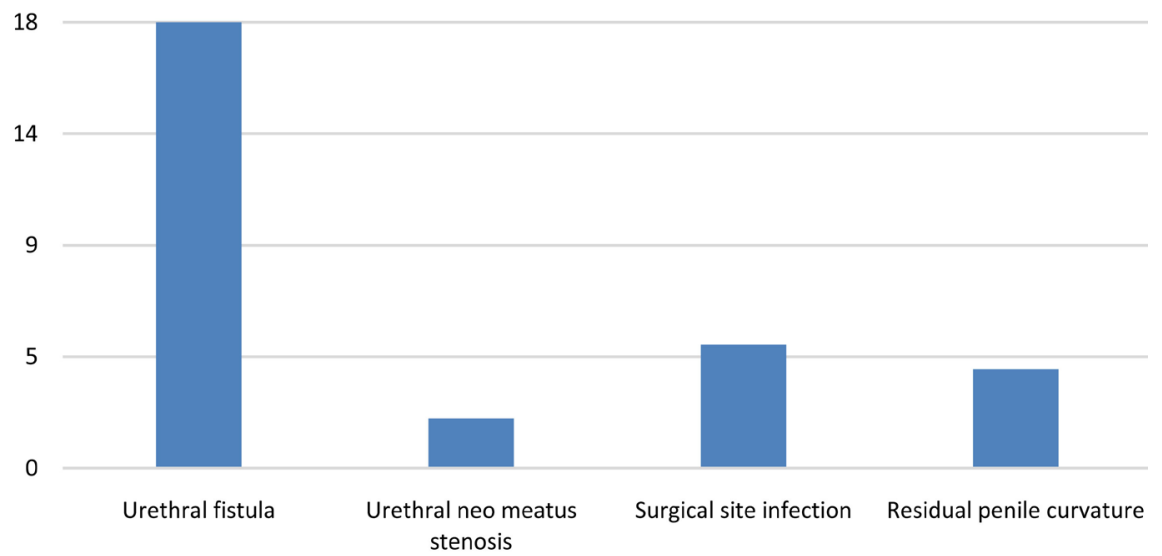

Figure 1. Distribution of patients according to postoperative complications $(n=29)$.

Table 1. Distribution of patients according to the type of penile straightening.

\begin{tabular}{ccc}
\hline Types of adjustment & Number & Percentage (\%) \\
\hline Release of adhesions only & 20 & 57.1 \\
Release of adhesions + Urethral plaque section + Nesbitt & 7 & 20 \\
Release of adhesions + dorsal plicature of the albuginea & 6 & 17.1 \\
Adhesion release + Urethral plaque section & 2 & 5.8 \\
\hline
\end{tabular}

Table 2. Distribution of patients depending of the types of uretroplasty and treatment outcome $(\mathrm{n}=55)$.

\begin{tabular}{cccc}
\hline Types of urethroplasty & Frequency & Good & Bad \\
\hline Duplay-Snodgrass & 23 & 21 & 2 \\
Duplay & 15 & 12 & 3 \\
DUPLAY + DUCKETT & 4 & 2 & 2 \\
Mathieu/urethroplasty & 3 & 3 & 0 \\
Duckett & 3 & 2 & 1 \\
ONLAY & 3 & 3 & 0 \\
Mustarde & 2 & 0 & 2 \\
MAGPI/Balanoplasty & 1 & 1 & 0 \\
DUPLAY + KOFF & 1 & 1 & 0 \\
\hline
\end{tabular}

age group of patients under four years had the most good outcomes with a rate of 53.3\% ( $\mathrm{n}=24)$ of patients successfully treated. Among the patients without a history of treatment, $80 \%(n=36)$ had a good outcome. The relative risk of having a poor outcome in patients with a history of previous treatment was 7 . 
Urethroplasty according to Duplay-Snodgrass give the best outcome $(46.7 \%$ ( $\mathrm{n}=$ 21)). The treatment outcomes according to the type of urethroplasty are shown in Table 2. Eleven patients were concerned for the evaluation of the sexuality. Four patients were unreachable and four other patients refused the investigation. After a mean delay of $53 \pm 26$ months (with extremes of two and 10 years) for the three patients who accepted the survey, the sexual function was rated best in one patient (score 12) and average in the other two (score 9 each).

\section{Discussion}

Hypospadias is a congenital urogenital malformation frequently encountered in our daily practice. Surgery is the treatment of choice but it exist several problems related to the surgical technique or its postoperative complications. Hypospadias surgery can be performed at any age, however, most authors recommend surgery between 6 - 18 months [6]. In 1996, the American Academy of Pediatrics also recommended that elective surgery of the male external genitalia be performed at this age, after the first phase of penis growth [7]. A delay in the consultation was noted in our study with a median age of 6 years (P25 = 2.8 and P75 $=13$ years). This median age observed shows an improvement of this delay in consultation compared to other African studies, in particular those of Diallo $\mathrm{AB}$ et al. [4] in Guinea Conakry and Diao B et al. [5] in Senegal who reported a mean age of 8 and 7.2 years respectively. These difference can be explained by the population's awareness of this pathology. However, some hypospadias are still diagnosed in adulthood. In our study, the best outtcome were recorded in the age group under 4 years. Although there is still conflicting data as to whether age at surgery influence the complication rate [8] [9]. The Duplay technique is a reliable technique for anterior hypospadias and can be used for moderate forms according to Bouhafs [10] who, out of a series of 585 hypospadias operated by the Duplay technique, reported a low rate of complications ( $11 \%$ all complications). The urethral plate incision, popularized by Snodgrass, can also be used in anterior and moderate forms of hypospadias. It gives very few complications with satisfactory cosmetic outcomes, compared to Mathieu's technique [11]. In our study, the Duplay-snodgrass technique was the most commonly used technique with a success rate of $90 \%$. Which shows a perfect mastery of this technique by our surgeons. In the literature, some authors have shown an improvement in the outcome of the Duplay technique by combining it with the Snodgrass trick as done in our series. Acimi [12] in his study found that the Duplay technique alone was three times more complicated by fistula (9\%) than the Duplay-Snodgrass technique (3\%). So did O'Connor [13] and this is explained by the Snodgrass trick on the urethral plate, which lowers the tension on the edges of the sutures. A literature review by Snodgrass et al. [14] compared Mathieu's technique and Snodgrass's urethral plaque incising technique in surgery for anterior hypospadias in terms of complication rate, maximum urine output (Qmax), cosmetic appearance. For the complication rate, 23 publications since 
1990 concerning the incision of the urethral plaque and Mathieu's operation were identified without any difference being objectified in the occurrence of fistulas, stenosis of the meatus or stenosis of the urethra. Likewise, a study comparing Qmax in children operated on by these two techniques did not note any difference after a median follow-up of 20 months [15]. This finding was similar if the flowmeter is performed at variable postoperative times, from $<6$ months to $>10$ years [16]. Despite the existence of several surgical techniques, the success rate depends on the surgeon's experience whatever the technique chosen. The main complications of hypospadias surgery reported in the literature are surgical site infection, flap necrosis, urethral fistula, and neo-urethral or urethral neomeatus stenosis [4] [5] [17]. Urethral fistula was the predominant complication in our study. Surgical site infections where the second complication and were responsible for the loosening of sutures. These suppurations are favoured by the poor conditions in which postoperative care is provided, but also by the hot and dry tropical climate [4] [5]. The flap necrosis can be explained by the unavailability of adequate equipment for dissection and reconstruction (surgical loupes, fine wires for the sutures, microsurgical instruments, etc.) and the lack of a urologist who specializing in hypospadias in our regions. Lower complication rates are noted by other authors, especially in developed countries [18]. The evaluation of hypospadias surgery provides valuable information on the outcome, helps decision-making, improves performance and quality of care [19]. Several instruments aimed at measuring the satisfaction of patients with hypospadias were identified in the literature. Among them, the hypospadias objective assessment score, the pediatric penile perception score, the genital perception scale. However, most of these scores assess the postoperative cosmetic aspect and not the sexuality and the psychosocial sequelae [19]. We tried in our study to assess sexuality after treatment in adulthood. Among the 3 patients who accepted the survey about sexual function, one was married without children. Indeed, this small number of participating patients is a limit of this evaluation, and it was impossible to draw a conclusion. In the literature, the evaluation of sexual function in adulthood remains difficult because of its subjectivity [20]. It is necessary to study the fertility, ejaculation quality, sperm parameters and hormonal profile of these patients with a larger cohort in order to draw conclusions.

\section{Conclusion}

Urethroplasty according to Duplay Snodgrass was the most technique using in our studies with a satisfactory rate of good outcome. The complication rate observed was related to several factors, including the lack of adequate surgical equipment. The evaluation of the sexual function remained subjective in our study due the low rate of participant.

\section{Author's Contribution}

All authors have read and approved the final version of the manuscript. 


\section{Conflicts of Interest}

The authors do not declare any conflict of interest.

\section{References}

[1] Demède, D., de Mattose Silva, E., Gorduza, D. and Mouriquand, P. (2008) Actualités sur l'hypospade. Archives Francaises de Pediatrie, 15, 1366-1374. https://doi.org/10.1016/j.arcped.2008.06.001

[2] Wein, A., Campbell, M.F., Walsh, P.C. and Snodgrass, W. (2012) Campbell-Walsh Urology. 10th Edition, Elsevier, Amsterdam, 3503-3536.

[3] Mollard, P., Mouriquand, P. and Felfela, T. (1990) Traitement des hypospades. Editions Techniques-Encycl Méd Chir. (Paris, France), Techniques chirurgicales, UrolGynécol, 41340, 17.

[4] Diallo, A.B., Bah, I., Toure, B.M., Ouendeno, L.B., Balde, I. and Diallo, M.B. (2008) L'hypospadias: Aspects anatomo-cliniques et thérapeutiques au C.H.U de Conakry Guinée. Journal of Andrology, 18, 131-136. https://doi.org/10.1007/BF03040391

[5] Diao, B., Fall, P.A., Ndoye, A.K., Sow, Y., Diabaté, I., Niang, L., et al. (2006) La réparation en un temps de l'hypospadias antérieur. A propos de 40 cas. Dakar Medical, 51, 151-154.

[6] Manzoni, G., Bracka, A., Palminteri, E. and Marrocco, G. (2004) Hypospadias Surgery: When, What, and by Whom? BJU International, 94, 1188-1195. https://doi.org/10.1046/j.1464-410x.2004.05128.x

[7] Kass, E., Kogan, S.J. and Mainley, C. (1996) Timing of Elective Surgery on the Genitalia of Male Children with Particular Reference to the Risks, Benefits, and PsychoLogical Effects of Surgery and Anesthesia. Pediatrics, 97, 590.

[8] Yildiz, T., Tahtali, I.N., Ates, D.C., Keles, I. and Zekeriya, I. (2013) Age of Patient Is a Risk Factor for Urethrocutaneous Fistula in Hypospadias Surgery. Journal of Pediatric Urology, 9, 900-903. https://doi.org/10.1016/j.jpurol.2012.12.007

[9] Lu, W., Tao, Y., Wisniewski, A.B., Frimberger, D. and Kropp, B. (2012) Different Outcomes of Hypospadias Surgery between North America, Europe and China: Is Patient Age a Factor? Nephro-Urology Monthly, 4, 609-612. https://doi.org/10.5812/numonthly.1853

[10] Bouhafs, A., Mege, J.L., Dubois, R., Chaffange, P. and Dodat, H. (2002) Technique de Duplay modifiée dans le traitement de l'hypospadias. A propos de 585 cas. Annales d Urologie, 36, 196-203. https://doi.org/10.1016/S0003-4401(02)00099-2

[11] Akbiyik, F., Tiryaki, T., Şenel, E., Mambet, E., Livanelloglu, Z. and Atayurt, H. (2008) Clinical Experience in Hypospadias: Results of Tubularized Incised Plate in 496 Patients. Pediatric Urology, 73, 1255-1258. https://doi.org/10.1016/j.urology.2008.06.075

[12] Acimi, S. (2011) Comparative Study of Two Techniques Used in Distal Hypospadias Repair: Tubularized Incised Plate (Snodgrass) and Tubularized Urethral Plate (Duplay). Scandinavian Journal of Urology and Nephrology, 45, 68-71. https://doi.org/10.3109/00365599.2010.526959

[13] O'Connor, K.M. and Kiely, E.A. (2006) Lessons Learned Using Snodgrass Hypospadias Repair. Irish Journal of Medical Science, 175, 37-39. https://doi.org/10.1007/BF03168998

[14] Snodgrass, W. and Bush, N. (2016) Primary Hypospadias Repair Techniques: A Review of the Evidence. Urology Annals, 8, 403-408.

https://doi.org/10.4103/0974-7796.192097 
[15] Scarpa, M.G., Castagnetti, M., Berrettini, A., Rigamonti, W. and Musi, L. (2010) Urinary Function after Snodgrass Repair of Distal Hypospadias: Comparison with the Mathieu Repair. Pediatric Surgery International, 26, 519-522. https://doi.org/10.1007/s00383-010-2569-6

[16] Hueber, P.A., Antczak, C., Abdo, A., Franc-Guimond, J., Barrieras, D. and Houle, A.M. (2015) Long Term Functional Outcomes of Distal Hypospadias Repair: A Single Center Retrospective Comparative Study of TIPs, Mathieu and MAGPI. Journal of Pediatric Urology, 11, 68.e1-7. https://doi.org/10.1016/j.jpurol.2014.09.011

[17] Spinoit, A.-F., Poelaert, F., Groen, L.-A., Van Laecke, E. and Hoebeke, P. (2013) Hypospadias Repair at a Tertiary Care Center: Long-Term Follow-Up Is Mandatory to Determine the Real Complication Rate. Journal of Urology, 189, 2276-2281. https://doi.org/10.1016/j.juro.2012.12.100

[18] Keays, M.A. and Dave, S. (2017) Current Hypospadias Management: Diagnosis, Surgical Management, and Long-Term Patient-Centred Outcomes. Canadian Urological Association Journal, 11, S48-S53. https://doi.org/10.5489/cuaj.4386

[19] Sullivan, K.J., Hunter, Z., Andrioli, V., et al. (2017) Assessing Quality of Life of Patients with Hypospadias: A Systematic Review of Validated Patient-Reported Outcome Instruments. Journal of Pediatric Urology, 13, 19-27.

https://doi.org/10.1016/j.jpurol.2016.11.010

[20] Castagnetti, M., Scarpa, M.G., Musi, L. and Rigamonti, W. (2009) Evaluation of Cosmetic Results in Uncomplicated Distal Hypospadias Repairs. Journal of Andrological Sciences, 16, 121-124. 